\title{
The Success of the Global Business Leader: The Expatriate Perspective in Ghana
}

\author{
Joseph Kwadwo Tuffour \\ University of Professional Studies, Accra \\ Ebenezer Matey \\ Trias Ghana
}

In a fast-changing environment, both local and international companies have found that, one of the principal problems involve the failure to effectively manage people issues. The study examines the competencies that make a successful global leader from the expatriates' perspective in the nongovernmental organizations' sector of Ghana. Questionnaires were administered to 300 expatriates and Ghanaians who have worked abroad. Data from the survey were analysed using correlation and regression techniques. The results of the study indicate a statistical significant effect of each of managers' ability to appreciate cultural diversity, use of appropriate technology and proper decision-making on the success of global leaders' performance. The study revealed that, while age of the expatriates does not make any difference in determining success, the level of education and experience do have significant correlations with the success rate of expatriates' performance. It is therefore recommended that, organizations should aim at developing policies which embrace competences such as appreciating cultural diversity and using appropriate technology for decision-making in global organizations.

Keywords: Success of the Global Leader, Expatraites, Expatriate Perspective, Ghana

\section{INTRODUCTION}

The globalization of industries has led to the relentless quest by organizations worldwide for global leaders who can help their companies survive, and perhaps thrive in a highly competitive environment (Conner, 2000, p.13; Brewster, Bonache, Cerdin \& Suutari, 2014). In the knowledge-based and highly networked global economy, Conner (2000, p.13) and Zhu, Cieri and Zhang (2018) believe people are pivotal to a firm's competitive advantage since technology, capital and information cannot be mobilized effectively and efficiently in the absence of people. A lot has been written about the characteristics and competencies needed by global leaders (Morrison, 2000; Schmidt, Conaway, Easton \& Wardrope, 2007), however, the reality remains that, most leaders from developing countries have often been excluded from appointments and/or promotions to such leadership positions. This is due to the fact that, such leaders appear to lack one of the critical competencies identified for such key roles, namely the possession of a global mindset. In determining this, the competency is often estimated by whether the candidate in question has successfully completed a high-profile international assignment or not. Even though there are 
alternative paths to the development of a global orientation, most experts consider international assignments as one of the most effective mechanisms (Morrison, 2000).

Virtually all aspects of an assignee's daily life and work experience in the view of Morrison (2000, p.32) are challenged in a foreign environmental setting (Brewster et al., 2014). To survive, Morrison (2000, p. 32) believes the assignee has to recognize and learn that, there are alternatives, yet equally valid ways of perceiving reality and doing things around the world beyond those that one grew up with. However, as long as local leaders remain under-represented in international assignments, they will continue to lack the opportunity to acquire one of the critical competencies required of global leaders.

Schmidt, Conaway, Easton and Wardrope (2007, p. 44) reported that, globalization has increased workforce diversity in almost every industry around the world, which is believed calls for leaders who meet up with current challenges. More than ever, companies compete on the basis of how effectively they can integrate and synthesize the knowledge of their individual members, raising essential questions about ways to coordinate people of different backgrounds to promote organizational goals (Schmidt et al., 2007, p. 45). According to Vesa (2002, p. 122), the requirements in business life have changed and companies are modifying their strategies and practices. However, one of the major tools for developing such international managers has been suggested to be an international assignment. In line with this, Derr (1993, p. 31) states that, expatriation is one of the leading strategies for internationalizing a young manager. In addition, Conner (2000, p. 132) states that, a variety of assignments in different geographical locations were the best preparation for senior global leadership positions if global leaders intend to succeed. McCall and Hollenbeck (2002) noted that, for a global leader to succeed, there is the need for exposure which involves interaction by focusing on people and roles.

In Ghana, most international non-governmental organizations use expatriates to fill important leadership positions. However, there is pressure for such leaders to ascend to higher positions and thus, lead larger international organizations. This can be difficult for expatriates without proper understanding of the cultural nuances which exist and operate in Ghana. In such a given situation, expatriates who are unable to adapt to the Ghanaian cultural values and existing interpersonal relationships will suffer. This raises the problem of what type of competencies are required and to what extent do they affect a successful global leader? As organizations conduct a growing share of operations outside their home countries, such organizations should have a strong ability to attract and develop workers to effectively perform global tasks. These leaders should actively influence, motivate and help people at a global level to provide competitive advantage for the organizations they work with.

Some challenges that can impede the Ghanaian from becoming global leaders include balancing the benefits of standardization. This should be done in tandem with the need for local host country adaptation, managing teams across different geographical areas and time zones, and working through uncertain environments. Indicators are that, global leaders with the required skills can perform well in global environments. In building a global leadership pipeline, companies have to assess their current leaders, develop a succession plan and actively move leaders around the business to develop growth. Although the concept of globalization has received much attention in recent times, many organizations are unable to effectively facilitate global mindset transformation in the workplace (Oddou, Mendenhall \& Ritchie, 2000). Also, McDonough and Kahn (1997) state that, most companies have found that the principal problems involve the failure to effectively manage people issues. Leaders' competence and its consequences are an important, but understudied in Ghana, is a cause for concern. There is little published research on the expatriates' competencies and how they affect organizational performance. Thus, the leadership qualities of expatriate which are associated with higher organizational performance become critical. The study therefore, seeks to investigate the competencies that are required for the success of the global leader from the expatriates' perspective. The rest of the paper is structured as follows. Literature review is in section two while methodology is in section three. Section four contains the results and discussion of findings. Conclusion and policy implications are in section five. 


\section{LITERATURE REVIEW}

Many researchers have documented leadership theories involving traits, situational interaction, function, behaviour, power, charisma and intelligence. Early leadership theories focused on what qualities distinguished leaders from followers, while subsequent theories looked at other variables such as situational factors and skill levels. The Great Man Theory assume that the capacity for leadership is inherent, that great leaders are born and not made. The theory often portrays great leaders as heroic and destined to rise to leadership when needed. Similar to Great Man theory is the Trait Theory which assumes that, people inherit certain qualities and traits that make them better suited for leadership. The Trait Theory suggests that, individual personalities are composed of broad dispositions (Carlyle, 2002).

Early researchers focused their attention on traits of individuals as factors for determining what makes a person a leader. The writers of the trait theory believe that leaders were born and not made, this believe and approaches became known as the Great-man theory (Stogdill, 1974; Daft, 2005). Daft (2005) noted that leaders were believed to possess certain qualities that lead them to greatness under the trait theory. Knight, Shteynberg and Hanges (2011) also posited that in the 1950s and 1960s, leadership researchers mainly focused their attention on identifying the behaviors of effective leaders only. According to Slocum and Hellriegel (2007), the Trait theory failed to define specific traits that distinguish between successful and unsuccessful leaders. This failure of the Trait approach has resulted in scholars' quest to study other variables such as behaviors and actions of leaders.

Contingency theories of leadership focus on the environment which determines the particular style of leadership that is best suited to the situation. According to this theory, no leadership style is best in all situations. Success depends upon a number of variables, including the leadership style, qualities of the followers and aspects of the situation (Carlyle, 2002). Situational theories proposed by Carlyle (2002) indicate that, leaders choose the best course of action based upon situational variables. Different styles of leadership may be more appropriate for certain types of decision-making. Burmeister (2003) pointed out that, the Contingency theories of leadership seem to maintain that, effective leaders need to adjust and modify their styles in a given situation to suit that of the subordinates.

Carlyle (2002) believes that participative leadership theories suggest that, the ideal leadership style is one that takes the input of others into account. These leaders encourage participation and contributions from group members and help group members feel more relevant and committed to the decision-making process. Participative leadership behavior has to do with involving as well as inviting subordinates to share in the decision-making. This is where the leader consults with subordinates, obtain their views and incorporate their suggestions and ideas into the final decisions about how the group or organization will advance (Northouse, 2010). In the words of Negron (2008), the participative leader shares responsibilities with subordinates by involving them in the planning, decision-making and implementation stages. Management theories or transactional theories usually focus on the roles of supervisors, organizations and group members in performance. These theories use a system of rewards and punishments. Managerial theories are often used in business; when employees are successful, they are rewarded; when they fail, they are reprimanded or punished (Northouse, 2010). Apart from this, relationship theories (transformational theories), focus upon the connections formed between leaders and followers. Transformational leaders motivate and inspire people by helping group members see the importance and higher good of the organizational performance or task. Transformational leaders focused on the performance of group members. Such leaders also prefer individuals to fulfill their potential. Leaders with this style often have high ethical and moral standards (Weber \& Henderson, 2012). Further, the success or failure of a global leader either in local or global level depends on a number of factors: chief among them being the kind of leadership style adopted such as authoritarian, participative, transactional, transformational, democratic or laissez-faire style.

Functional leadership theory (Hackman \& Walton, 2010) is a particularly useful theory for addressing specific leader behaviors expected to contribute to organizational or unit effectiveness. This theory argues that, the leader's main job is to see that whatever is the need of the group is addressed. Thus, leaders can

Journal of Applied Business and Economics Vol. 21(9) 2019 
be said to have done their job well when they have contributed to group effectiveness and cohesion (Fleishman, 1991; Hackman \& Walton, 2010).

In a research conducted by Marks (2001) about client service, it was indicated that, expressions of positive attitude and a holistic approach to issues by the leader improve the performance of the group and contributes to the success of the global leader. The leader creates situations and events that lead to emotional response. Leaders shape workplace affective events. Examples include giving of feedback, allocating tasks and resource distribution. Since employees' behavior and productivity are directly affected by their emotional states, it is imperative for the leader to consider employees emotional responses to organizational performance since the success of the global leader is partly attributed to the employees. Emotional intelligence, the ability to understand and manage moods and emotions in one's self and others, contributes to effective leadership in organizations (Marks, 2001).

\section{METHODOLOGY}

\section{Methods and Sampling}

The study employed a cross-sectional survey design using primary data. Data was obtained from expatriates working in Ghana and Ghanaians who have worked abroad for a minimum of one year. A questionnaire was developed to collect data on perception of success and the competencies needed for success from the expatriates perspective. The questions were closed ended and contained questions bordering on respondents' demographic characteristics, success rate and competencies of global leaders. The population of the study was all expatriates working in Ghana and Ghanaians who have worked abroad for a minimum of one year. The study employed quantitative techniques. The sample size was 300 expatriates (only those in senior leadership positions and those serving in critical positions in organizations were selected).

The primary data was collected from 300 leaders working in 45 Non-Governmental Organisations (NGOs) (both international and local) operating in Northern Ghana (Upper East, Upper West and Northern Regions). The choice of the 45 NGOs in Northern Ghana was influenced by concentrations of NGOs operating in Northern Ghana as well as the diversity of staff employed by these NGOs. Respondents engaged in the survey were requested to determine the extent of agreement to selected leadership competences.

\section{Model and Data Analysis}

The answered questionnaires were vetted, coded and numbered sequentially. Quantitative approaches in analyzing the data collected were used. The statistical analysis was done by employing correlation and regression techniques to arrive at the conclusions. The regression equation was computed as the success as global leaders (Y) as a function of competences of the leader (C):

$\mathrm{Y}=f$ (competences of global leader)

However, empirical evidence suggests that there are a number of other individual and environmental factors $\left(X^{*}\right)$ which could directly influence global leaders (Zhu et al., 2018, Lin \& Lin, 2014; Morgan, 2004). Demographic and environmental factors such as gender, age, education and experience of people are included as control variables, because literature has found such characteristics to influence the interaction between supervisors and subordinates, and thus affect outcomes including individual and firm performance (Russ \& McNeilly, 1995; Wiener, 2001; Stierle, van Dick \& Wagner, 2002; Nunnally, 2014; Tuffour, Barnor \& Akuffo, 2015; Tuffour, Akuffo, Kofi, Frimpong \& Sasu, 2018; Tuffour, Abubakari \& Tuffour, 2019).

$\mathrm{Y}=\mathrm{f}\left(\mathrm{C}, \mathrm{X}^{*}\right)$

However, competence is made up of: 
i. Appreciating cultural diversity (ACD)

ii. $\quad$ Thinking globally (TG)

iii. Technological savvy (TS)

iv. Building partnerships and alliances (BPA)

v. Decision-making (DM)

$\mathrm{X}^{*}=\mathrm{a}$ set of control variables (age, gender of leaders, experience of leaders, level of education of leaders)

\section{Model Specification}

In the present study, based on literature, the success of global leaders is measured by the perception of growth which is a dummy variable (1 for perception of success and 0 otherwise), which require the use of a logistic regression. Mathematically, the logistic regression model is specified as:

$$
\log i t(y)=\log \left[\frac{p(y=1)}{1-p(y=1)}\right]=\beta_{0}+\beta_{1} X_{t 1}+\beta_{2} X_{t 2}+\beta_{3} X_{t 3}+\ldots+\beta_{n} X_{t n}+\varepsilon_{t}
$$

For $i=1, \ldots, n ; \varepsilon \sim N\left(0, \sigma^{2}\right), \mathrm{y}^{\prime} \in(-\infty, \infty), p(y=1)$ is the predicted probability of the event which is coded as 1 rather than as 0 and $X s$ are the predictor variables. The $\beta s$ are the coefficients while $t$ is the crosssectional period.

By inclusion of the relevant variables, model (3) becomes

$$
\begin{aligned}
& \mathrm{Y}=\beta_{0}+\beta_{1} \mathrm{ACD}_{\mathrm{t}}+\beta_{2} \mathrm{TG}_{\mathrm{t}}+\beta_{3} \mathrm{TS}_{\mathrm{t}}+\beta_{4} \mathrm{BPA}_{\mathrm{t}}+\beta_{5} \mathrm{DM}_{\mathrm{t}}+{ }_{\mathrm{\gamma}} \mathrm{X}_{\mathrm{t}}+\varepsilon_{\mathrm{t}} \\
& Y=\beta_{0}+\beta_{1} A C D_{t}+\beta_{2} T G_{t}+\beta_{3} T S_{t}+\beta_{4} B P A_{t}+\beta_{5} D M_{t}+\alpha_{1} \text { age }_{t}+\alpha_{2} \text { gender }_{t} \\
& +\alpha_{3} E d u_{t}+\alpha_{4} \operatorname{Exp}_{t}+\varepsilon_{t}
\end{aligned}
$$

where:

$\mathrm{Y}=$ successful global leader, defined as the dummy variable, where $1=$ yes I have succeeded and 0 otherwise.

$\beta=$ coefficients, which show the direction of effect of competences on success of global leader. Mean scores of the various competence variables of successful global leader were used for the analysis.

$\boldsymbol{\varepsilon}=$ Random error term

$\beta_{1}, \beta_{2}, \beta_{3}, \beta_{4}$ and $\beta_{5}$ are the coefficients of regression, it is expected that $\beta_{1}>0 ; \beta_{2}>0 ; \beta_{3}>0 ; \beta_{4}>0$; and $\beta_{5}$ $>0$.

\section{RESULTS AND DISCUSSION OF FINDINGS}

\section{Validity and Reliability}

The study evaluated the overall fitness of the study instrument. The construct validity is ascertained since the instrument is used in a new setting. Reliability test embraces quality criteria, made of the composite reliability and Cronbach's alpha. If the composite reliability and Cronbach's alpha measurements have coefficients of 0.7 and above, they show that variables have acknowledged reliability. The results in table 1 shows that, the constructs are all reliable and valid. 
TABLE 1

RELIABILITY TEST RESULTS

\begin{tabular}{lll}
\hline Variables & Cronbach's Alpha & Composite Reliability \\
\hline Thinking globally & 0.788 & 0.852 \\
Appreciating cultural diversity & 0.812 & 0.952 \\
Technological savvy & 0.772 & 0.867 \\
Building partnerships and alliances & 0.841 & 0.977 \\
Decision-making & 0.843 & 0.856 \\
\hline
\end{tabular}

Source: Authors' Calculations

\section{Demographic Characteristics of Respondents}

The age distribution of respondents therefore ranged from 20 and above (See Table 2). Overall, 105 of the respondents representing $35.0 \%$ are in the 30-39 age group, whiles 135 of respondents representing the highest percentage of 45.0 are within the 40-49 age group. It was therefore observed that, there are a greater percentage of the expatriates working in Ghana and Ghanaians who have worked abroad within 30-49 age bracket showing clearly that, the maturity of leaders in terms of age are considered in taking global assignments.

TABLE 2

AGE DISTRIBUTION OF RESPONDENTS

\begin{tabular}{lcc}
\hline Age Group & Frequency & Percentage \\
\hline $20-29$ years & 24 & 8.0 \\
$30-39$ years & 105 & 35.0 \\
$40-49$ years & 135 & 45.0 \\
50 and above & 36 & 12.0 \\
Total & $\mathbf{3 0 0}$ & $\mathbf{1 0 0}$ \\
\hline
\end{tabular}

Source: Authors' Calculation

Out of the total number of 300 respondents who were interviewed, a total of 249 were males representing the highest percentage of 83 , whiles 51 of them are females representing the minority percentage of 17. The higher frequency of respondents being males indicates that, majority of the expatriates working in Ghana and Ghanaians who have worked abroad are mostly males.

TABLE 3

EDUCATIONAL QUALIFICATION OF RESPONDENTS

\begin{tabular}{lcc}
\hline Educational Level & Frequency & Percentage \\
\hline HND & 21 & 7.0 \\
Undergraduate Degree & 92 & 30.7 \\
MBA & 131 & 43.7 \\
PhD & 56 & 18.7 \\
Total & $\mathbf{3 0 0}$ & $\mathbf{1 0 0}$ \\
\hline
\end{tabular}

Source: Authors' Calculation

The educational qualification of respondents as seen in Table 3 shows that, MBA and $\mathrm{PhD}$ degrees constitute majority of respondents' highest level of education, representing a total percentage of 62.4. Those who hold Higher National Diploma (HND) Certificate constitute only $7.0 \%$. Close to 100 of the respondents who provided data were undergraduate degree holders with a total percentage of 30.7 . The 
level of education helps to test the respondents' understanding of issues concerning global leadership and competences that can contribute to their success as global leaders. From the above, it can then be inferred that, majority of expatriates working in Ghana and Ghanaians who have worked abroad have high levels of formal education.

NUMBER OF YEARS OF WORKING EXPERIENCE IN GHANA AND ABROAD

\begin{tabular}{lcc}
\hline Years of Experience & Frequency & Percent \\
\hline Less than 1 year & 57 & 19.0 \\
1 - 3 years & 99 & 33.0 \\
4 - 6 years & 114 & 38.0 \\
6 years and above & 30 & 10.0 \\
Total & $\mathbf{3 0 0}$ & $\mathbf{1 0 0 . 0}$ \\
\hline
\end{tabular}

Source: Authors' Calculation

In indicating how long expatriates have worked, a total number of 57 out of the 300 respondents representing 19\% (see Table 4) stated that, they have been working outside their country of origin for less than a year. A minimal of 30 respondents indicated that they have been working outside of their home country for 6 years and above (with a percentage of 10\%). Majority of expatriates have been working between 1 to 6 years, totaling 72\%. According to Connor (2000), the length of time spent by expatriates to gain experience is very important to assess the performance of an expatriate in a given host country.

TABLE 5

FACTORS FACILITATING THE SUCCESS OF AN EXPATRIATE

\begin{tabular}{lcc}
\hline Competency Issue & Frequency & Percentage \\
\hline Experience & 9 & 3.0 \\
Competence & 138 & 46.0 \\
All the above & 153 & 51.0 \\
Total & $\mathbf{3 0 0}$ & $\mathbf{1 0 0 . 0}$ \\
\hline
\end{tabular}

Source: Authors' Calculation

The primary data collected and analyzed concerning factors leading to the success of expatriates as shown in table 5 indicates that, a larger percentage of expatriates working in Ghana and Ghanaians who have worked abroad succeed mostly as a result of the experience and competence they have. Out of a total number of 300 respondents, $51 \%$ of them are of the view that, the success of an expatriate mostly depends on both their experience and their level of competence. However, $46.0 \%$ are of the opinion that, it takes the competence of the expatriate to succeed. These responses show the level of diversity of factors that can lead to the success as expatriates. From the discussion, majority of expatriates either working in Ghana or Ghanaian who have worked abroad confirm that, they always succeed on any kind of mission they embarked on. Out of the total number of respondents, $52 \%$ of them answered in the affirmative to indicate that, they succeed in any kind of mission they have ever embarked on, whiles 144 of respondents, constituting $48 \%$ answered otherwise, indicating that they do not always succeed in all kinds of missions they have ever embarked on.

The study therefore found that, majority of respondents attributed their inability to always succeed in all kinds of missions they have ever embarked on to a number of factors including but not limited to (see Figure 1) unfavorable working conditions, cultural diversity and the legal issues of the foreign countries they have been to. 
FIGURE 1

CHALLENGES FACED BY EXPATRIATES

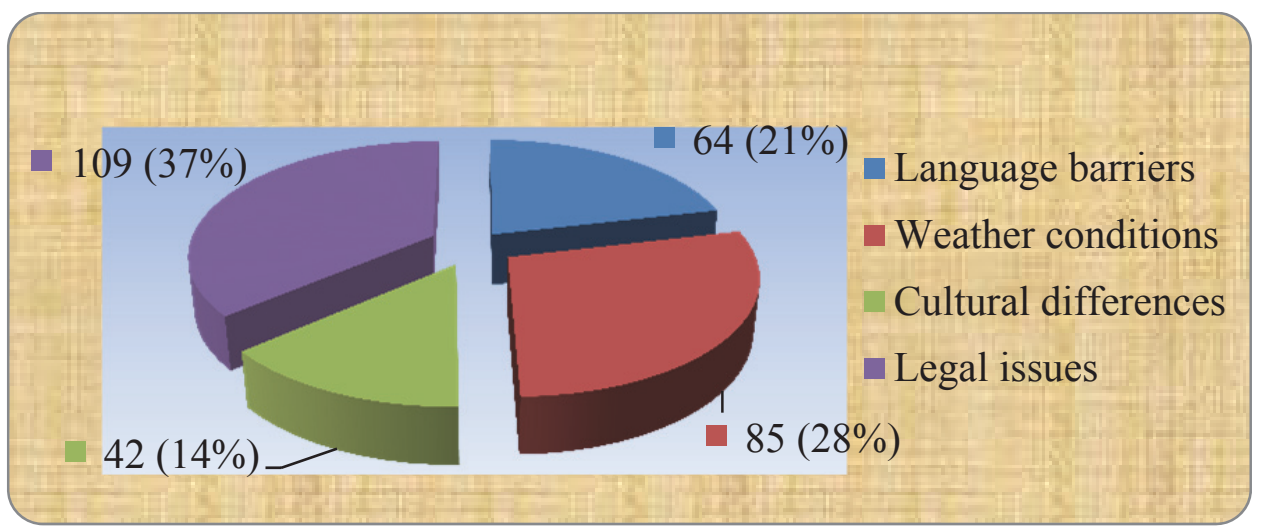

Source: Authors' Development

All the 300 respondents to whom questionnaires were administered to, identified some challenges that contributed to their inability to be completely successful in all their activities (see Figure 1). Out of the total sample, 64 of them representing $21.3 \%$ believed that there is a language barrier which sometimes makes it embarrassing and frustrating in communicating simple policy. Also, 85 of them representing $28.3 \%$ have to adapt to weather conditions, which is totally different from that of their home country. This affects their level of productivity, leading to their inability to perform creditably.

A total of 42 of them (with a percentage of 14) are also of the view that, the worst challenge they encounter when working abroad is the cultural differences they have to endure. Nonetheless, majority of expatriates both working in Ghana and Ghanaians who have worked abroad, attributed the most challenging factor they faced when working abroad to the issue of legality. They believe the legal environment in their home country is not as the same as the type they encounter on the foreign country. For an expatriate to succeed, there is the need to understand the legal issues in the host country.

\section{Correlation Test Results}

Table 6 shows that, expatriates who are able to appreciate cultural affinity of the host country, ability to think globally, use appropriate technology (as earlier revealed by Morgan et al., 2004) and those who build partnerships have significant positive correlation with propensity to succeed in their work as revealed by Morgan et al. (2004). Although making the right decision is positive, it does not significantly correlate with leader success. From the results, being a male does not necessarily make an expatriate to succeed. In addition, as the expatriate's age, the ability to succeed falls. This is expected, as the strength required to undertake monitoring and other supervisory activities which require travel reduces. Moreover, it is revealed that, the higher the level of education, the more the propensity to succeed. Lin and Lin (2014) revealed the significance of culture and expatriate experience. Experience has a significant positive relationship with the propensity to succeed. Stierle et al. (2002) revealed the importance of individual manager's characteristics. 
TABLE 6

CORRELATION MATRIX

\begin{tabular}{|c|c|c|c|c|c|c|c|c|c|c|}
\hline & $\mathrm{Cul}$ & Think & Tech & Dec & Part & Gender & Age & Educ & Exp & Success \\
\hline \multicolumn{11}{|l|}{ Cul } \\
\hline Think & $0.140^{* *}$ & & & & & & & & & \\
\hline Tech & 0.029 & $0.398^{* *}$ & & & & & & & & \\
\hline Dec & $-0.120^{*}$ & -0.068 & 0.034 & & & & & & & \\
\hline Part & 0.076 & $0.137^{*}$ & 0.046 & $0.123^{*}$ & & & & & & \\
\hline Gender & $0.244^{* *}$ & -0.013 & -0.040 & $-0.145^{*}$ & 0.010 & & & & & \\
\hline Age & $-0.187^{* *}$ & $-0.166^{* *}$ & 0.033 & 0.068 & -0.112 & $-0.125^{*}$ & & & & \\
\hline Educ & $-0.197^{* *}$ & -0.088 & 0.089 & $0.132^{*}$ & $-0.101^{*}$ & $-0.179^{* *}$ & $0.245^{* *}$ & & & \\
\hline Exp & 0.020 & 0.009 & 0.030 & 0.007 & 0.026 & 0.011 & 0.071 & 0.077 & & \\
\hline$\overline{\text { Success }}$ & $0.544^{* *}$ & $0.754^{* *}$ & $0.526^{* *}$ & 0.100 & $0.415^{* *}$ & 0.075 & $-0.183^{* *}$ & $0.119^{*}$ & $0.851 * *$ & 1.00 \\
\hline \multicolumn{11}{|c|}{$\begin{array}{l}\text { *. Correlation is significant at the } 0.05 \text { level (2-tailed). } \\
* * \text {. Correlation is significant at the } 0.01 \text { level (2-tailed). }\end{array}$} \\
\hline $\begin{array}{l}\text { Source: Autho } \\
\text { Notes: } \\
\text { Think = Thinl } \\
\text { alliances, App }\end{array}$ & $\begin{array}{l}\text { ors' calculat } \\
\text { king globall } \\
\text { prec = Appre }\end{array}$ & tions & 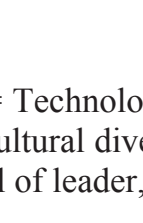 & 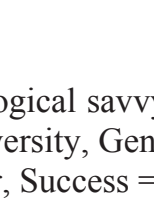 & 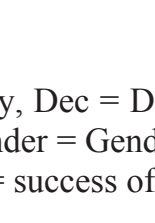 & . & 10 & $=\mathrm{B}$ & 0 & and \\
\hline
\end{tabular}

\section{Results of Regression Analysis}

The purpose of the study is to examine the competencies that determine a successful global leader from the expatriate perspective. Competences of global leader is regressed on the success of a global leader using primary data. The factors of competencies are appreciating cultural diversity, thinking globally, technological savvy, building partnerships and alliances and decision-making. The regression analysis conducted however gave an overall F-statistic value of 5.734 which is significant at the 0.05 significance levels (Table 7). This means that, success of a global leader is strongly dependent on competences of the global leader factors. The table 7 summarizes the results of the multiple regression analysis in relation to the competences of a global leader from the expatriate perspective.

The regression analysis indicated strong dependence on the competence of the global leader particularly appreciating cultural diversity and decision-making. Further analysis on the factors contributing to the success of the global leader unearthed high positive significant effect of decisionmaking, developing technological savvy and appreciating cultural diversity. Morgan et al. (2004) found similar results for technology. Lin and Lin (2014) indicate that, culture is a key factor in determining success. Building partnerships and alliances, and ability to think globally also showed positive effect on success. However, other leadership qualities such as managing change, strategic thinking, enabling teams and managing results are required for overall organizational performance. There is a strong effect from cultural assimilation to successful performance in organizations in different societies. This makes it extremely important to consider and modify one's leadership and management style to fit the societal norms and culture of the foreign country.

With regards to the transformation of local organizations to a more globally competitive organizations, it is suggested that, general leadership skills are easily transferred into a global leadership context. However, this does not mean a leader who is effective in a domestic setting will necessarily be effective in a foreign setting. 
TABLE 7

MULTIPLE REGRESSION ANALYSIS RESULTS

\begin{tabular}{lccccc}
\hline & \multicolumn{2}{c}{$\begin{array}{c}\text { Unstandardized } \\
\text { Coefficients }\end{array}$} & $\begin{array}{c}\text { Standardized } \\
\text { Coefficients }\end{array}$ & $\begin{array}{c}\mathbf{t} \\
\text { Stats }\end{array}$ & Sig. \\
\hline Competency Issue & B & Std. Error & Beta & & \\
\hline Constant & 0.873 & 1.017 & & 0.858 & 0.393 \\
Appreciating cultural diversity & 0.274 & 0.069 & 0.408 & 3.957 & 0.000 \\
Building partnerships and alliances & 0.064 & 0.063 & 0.101 & 1.011 & 0.315 \\
Thinking globally & 0.013 & 0.089 & 0.014 & 0.150 & 0.881 \\
Developing technological savvy & 0.129 & 0.078 & 0.149 & 1.690 & 0.100 \\
Decision-making & 0.491 & 0.157 & 0.293 & 3.136 & 0.002 \\
\hline
\end{tabular}

Source: Authors' calculations

\section{CONCLUSIONS AND POLICY IMPLICATIONS}

The study set out to examine the competencies that make a successful global leader from the expatriate perspective in the non-governmental organizations sector in Ghana. Within the limits of the study, the results of the study have shown conclusively that competencies such as appreciating cultural diversity, proper decision-making and appropriate use of technology have significant effect on, and relationship with the success of global leader. In an effort to transform local organizations into global competitive ones, organizations should develop and uphold policies that embrace competences such as appreciating cultural diversity, proper decision-making and applying appropriate technology.

Based on the results of the study, the following policy recommendations are made: first, global organizations should make conscious efforts to facilitate cultural assimilation by providing employees with baseline cross cultural information, appropriate levels of oversight, support and feedback. Also, the creation of opportunities for reflection, fostering an open culture built on personal relationships, and facilitating access to internationally experienced coaches, mentors, and role models are key in developing global leaders.

Second, organizations should aim at developing global mindset. A global mindset can be the new competitive advantage in the marketplace. Global executives must take much more responsibility for their own development. The complex and dynamic world in which we live provides unlimited opportunities for exploring the many linkages across our wide world of diversity.

\section{REFERENCES}

Brewster, C., Bonache, J., Cerdin, J., \& Suutari, V. (2014). Exploring expatriate outcomes, The International Journal of Human Resource Management, 25(14), 1921 1937, DOI: 10.1080/09585192.2013.870284.

Burmeiste, W. (2003). Leadership simplified: Abandoning the Einsteinian "unified field theory" approach. Journal of American Academy of Business, 3, 152-156.

Carlyle, R. S. (2002). A manager's guide to globalizations: Six keys to success in a changing world. Business One Irwin, Homewood, IL.

Conner, J. (2000). Developing the global leaders of tomorrow. Human Resource Management, Summer/Fall, 39 (2 \& 3), 147-157.

Daft, R. L. (2005). The leadership experience. Thomson-Southwestern, Vancouver.

Derr, B. C. (1993). Internationalizing managers: Speeding up the process. European Management Journal, 2(2), 435-442.

Fleishman, W. C. (1991). Developing global executives: Experience. Harvard Business School Press, Boston, MA.

Hackman, B., \& Walton, P. (2010). Effects of leadership style on team learning. Journal of Workplace Learning, 22(4), 228-248. 
Knight, A. P., Shteynberg, G., \& Hanges, P. J. (2011). Path-goal analysis, Encyclopedia of leadership. (1165-1170). Thousand Oaks, CA: SAGE Publications.

Lin, P., \& Lin, P. (2014). Key success factors in expatriate management in multinational medicine industry, Studies on Ethno-Medicine, 8(1), 43-49, DOI: 10.1080/09735070.2014.11886471.

Marks, B. B. (2001). Global leader development: Leadership development initiatives.

McCall, M. W. Jr., \& Hollenbeck, G. P. (2002). Developing global executives: The lessons of international experience. Harvard Business School Press: Boston, MA.

McDonough, E. F., \& Kahn, K. B. ( 1997). Using "hard" and "soft" technologies for global new product development. IEEE Engineering Management Review, 25, 66-75.

Morgan, L. O., Thunderbird, N., \& Young, S. T. (2004). Operational factors as determinants of expatriate and repatriate success. International Journal of Operations \& Production Management, 24(12), $1247-1268$.

Morrison, A. J. (2000). Developing a global leadership model. Human Resource Management, 39(2-3), 117-32.

Negron, D. (2008). A case study examining the relationship of the path-goal theory leadership styles to profits in El Paso, (Doctoral dissertation). Capella University.

Northouse, J. M. (2010). Leadership: Theory and practice, (5th ed.). Sage Publications, Califonia.

Nunnally, J. C. (2014). Psychometric theory. New York: McGraw-Hill.

Oddou, G., Mendenhall, M. E., \& Ritchie, J. B. (2000). Leveraging travel as a tool for global leadership development. Human Resource Management, Summer/Fall, 39(2 \& 3), 159-172.

Russ, F. A., \& McNeilly, K. M. (1995). Links among satisfaction, commitment and turnover intentions: The moderating effect of experience, gender and performance. Journal of Business Research, 34(1), 57-65.

Schmidt, W. V., Conaway, R. N., Easton, S. S., \& Wardrope, W. J. (2007). Communicating globally: Intercultural communication and international business. Sage Publications, Inc, 123.

Slocum, J. W., \& Hellriegel, D. (2007). Fundamentals of organizational behavior. SouthWestern/Cengage Learning, Mason.

Stierle, C., van Dick, R., \& Wagner, U. (2002). Success or failure? Personality, family, and intercultural orientation as determinants of expatriate managers' success, Zeitschrift für Sozialpsychologie, 33(4), 209-218.

Stogdill, R. (1974). Handbook on leadership. New York: Free Press.

Tuffour, J. K., Abubakari, M. G., \& Tuffour, M. K. (2019). Managerial leadership style and employee commitment: Evidence from the financial sector, Global Business Review, 1-18.

Tuffour, J. K., Banor, C., \& Akuffo, E. (2015). Do leadership styles matter in microfinance performance? Empirical evidence from Ghana, Journal of Business Research, 9, 1-15.

Tuffour, J. K., Akuffo, D., Kofi, A. A., Frimpong, P. A., \& Sasu, T. (2018). Adoption of mobile commerce and service in Adentan municipality of Ghana: An examination of factors influencing small enterprises, International Business Research, 11(11), 109-118. DOI:

10.5539/ibr.v11n $11 \mathrm{p} 109$

Vesa, S. (2002). Global leader development: An emerging research agenda. Career Development International, 7/4, 218-233.

Weber, M., \& Henderson, A. M. (2012). The theory of social and economic organization. Martino Fine Books, New York.

Wiener, H. (2001). Normative commitment as a mediator of the relationship between transformational leadership and followers' performance and organizational citizenship behaviour. Academy of Management Journal, 48(3), 420-432.

Zhu, C. J., De Cieri, H., Fan D., \& Zhang, M. M. (2018). Expatriate management in emerging market multinational enterprises (EMNEs): Reflection and future research agenda. The International Journal of Human Resource Management, 29(11), 1787-1798. DOI: 10.1080/09585192.2017.1335997. 